\title{
ACUPUNTURA URBANA: O Caso do Planejamento Estratégico de Barcelona/Es
}

\author{
Autor: Ana Luisa de Andrade \\ Centro Universitário FAG \\ Orientação: Andressa Carolina Ruschel \\ E-mail: analudeandrade@hotmail.com
}

\section{RESUMO}

Fundamentado sobre um dos mais emblemáticos planejamentos urbanos que a cidade de Barcelona/ES sofreu, o trabalho aborda como tema o plano para os Jogos Olímpicos de 1992, juntamente com o termo acupuntura urbana. Assim o objetivo geral se dá pelo anseio de compreender a relação que tal plano teve sobre a cidade, possibilitando a proposição de um caso de acupuntura urbana. Deste modo, o problema que instigou a pesquisa foi: De que forma o planejamento estratégico da cidade de Barcelona/ES pode ser considerado como um pleno exercício de caso de acupuntura urbana? Com isso, se pressupõem que a cidade, diante desse plano, insinua um caso de acupuntura urbana. As metodologias utilizadas foram a dialética, o estudo de caso, a revisão bibliográfica e o método de quadros. Assim, chegando ao arremate que o planejamento estudado pode ser considerado como um caso de acupuntura urbana, visto suas revitalizações e ações pontuais.

Palavras chave: Jogos Olímpicos, Barcelona, Acupuntura urbana.

\begin{abstract}
ABSTRAT
Based on one of the most emblematic urban plans that the city of Barcelona/ES has suffered, the paper approaches as the theme the plan for the 1992 Olympic Games, along with the term urban acupuncture. Thus the general objective is given by the desire to understand the relation that such plan had on the city, making possible the proposition of a case of urban acupuncture. Thus, the problem that instigated the research was: In what way can the strategic planning of the city of Barcelona / ES be considered as a full exercise in the case of urban acupuncture? With this, it is assumed that the city, before this plan, insinuates a case of urban acupuncture. The methodology used was the dialectic, the case study, the bibliographic review and the framework method. Thus, arriving at the completion that the planning studied can be considered as a case of urban acupuncture, since its revitalizations and punctual actions.
\end{abstract}

Keywords: Olympic Games, Barcelona, Urban Acupuncture. 


\section{INTRODUÇÃO}

Lamas (2000:111) menciona que "A cidade, como qualquer organismo vivo, encontra-se em continua modificação", visto que elas se formam como uma prática humana e, devido a um extenso processo histórico, vão se desenvolvendo, resultando em assentamentos urbanos com diversas características, funções e formas (SANTOS, 2014). Nesse sentido, o assunto que esta pesquisa abordará, será referente ao planejamento urbano, uma vez que, tal grupo de pesquisa é caracterizado por abranger a temática da cidade e seu planejamento, contando com dados históricos das cidades, com o desenvolvimento do espaço urbano e dos grupos humanos incorporados nesse espaço. Dessa maneira, o tema aborda de modo mais específico ao planejamento estratégico da cidade de Barcelona/ES correlacionado a um caso de acupuntura urbana.

Diante disso, o problema estimulador da pesquisa sintetiza-se pela seguinte indagação: De que forma o planejamento estratégico da cidade de Barcelona/ES pode ser considerado como um pleno exercício de caso de acupuntura urbana? Para essa problemática, partiu-se da hipótese inicial em que: A cidade de Barcelona/ES, em um de seus planejamentos mais marcantes, o plano para as Olimpíadas de 1992, alude a um íntegro caso de acupuntura urbana.

De tal modo, o objetivo geral do trabalho é compreender a relação, influência e contraposições que tal plano realizado em Barcelona/ES, tive sobre a cidade, possibilitando a proposição de um caso de acupuntura urbana. Portanto, para atingir tal objetivo, de modo mais específico foi elencado os seguintes artifícios: (I) Definir e compreender o conceito de planejamento estratégico e acupuntura urbana; (II) Abranger a história, percursos e limitações que a cidade de Barcelona/ES teve sobre a formulação do plano; (III) Analisar como o planejamento foi inserido sob a cidade de Barcelona/ES; (IV) Compreender como o termo acupuntura urbana, pode ser relacionado com a cidade e o plano estudado.

Abordando esta temática, evidencia-se a relevância da realização deste trabalho, visto que, pode ser justificado no domínio social, por gerar contribuições para a construção de um bem comum, proporcionando com isso, subsídios sobre o valor do planejamento urbano, uma vez que, é intrínseco o vínculo existente entre a sociedade e a cidade.

Já no campo acadêmico e científico, o projeto se define, por oferecer informações, juntamente com o designo de desencadear novas discussões e abordagens sobre o tema. No que diz respeito ao âmbito profissional, o intuito é de apresentar uma nova visão sobre a importância de um bom planejamento e como isso pode transformar uma sociedade, visto que, segundo Dias (2009, p.20) "Através do planejamento estratégico, gestores municipais têm condições de saber onde o município estava; onde quer chegar; como chegará".

\section{METODOLOGIA DA PESQUISA}

A metodologia aplicada na pesquisa foi uma Revisão Bibliográfica, a qual, para Marconi e Lakatos (2003), incide em um resumo de dados sobre os principais trabalhos de maior mérito ou influência já elaborados, os quais são capazes de fornecer informações imprescindíveis relacionadas ao tema. Já segundo Gil (2008), a principal vantagem da pesquisa bibliográfica pode ser definida pelo fato de possibilitar ao pesquisador uma maior abrangência de dados do que poderia ser pesquisado diretamente. Contudo, a pesquisa bibliográfica não é exclusivamente uma reprodução do que já foi efetuado sobre algum assunto, e sim um apoio ou referência, para novas análises, assim, por conseguinte, se obtêm descobertas e elaboração de conclusões inovadoras (MARCONI; LAKATOS, 2003).

Na pesquisa ainda se utiliza a dialética, a qual, segundo Gil (2008), tem por objetivo prover apoios para uma acepção dinâmica e total da realidade, uma vez que, esta metodologia estabelece ainda que, os fatos sociais não podem ser compreendidos quando considerados isoladamente. Já Marconi e Lakatos (2003), defendem que para o método dialético, um segmento de pesquisa encontra-se sempre em desenvolvimento, sendo que o determinado fim desse processo, pode ser o começo de outro.

Para aplicar o tema delimitado ao trabalho, foi utilizado o método de Estudo de Caso, que segundo Yin (2001) é um fato que investiga um fenômeno contemporâneo dentro de sua totalidade, principalmente quando os limites destes fenômenos e seu contexto não são visivelmente marcantes. Gil (2008), também defende que estudo de caso é uma pesquisa com diferentes propósitos, sendo eles: explorar circunstâncias da vida real, nas quais os limites não estão visivelmente definidos; apresentar a situação do contexto em 
que está sendo realizada determina averiguação e por último, explicar os inúmeros motivos de determinado acontecimento em situações muito complexas que não permitem a utilização de levantamentos e experimentos.

Dessa forma, para dar sustentação a análise, se utilizou na pesquisa uma metodologia de quadros, a qual tem por finalidade auxiliar na distinção e investigação das semelhanças e relações entre os assuntos abordados (MARCONI; LAKATOS, 2003). Tal medida, ainda colabora na obtenção de amplas informações, tornando a análise um amplo instrumento de comunicação (GIL, 2008).

\section{ASPECTOS CONCEITUAIS}

\subsection{Planejamento Estratégico: Princípios e definições}

Com o passar do tempo, e cada vez mais, as cidades estão assumindo um grande destaque tanto no campo político, econômico, social e cultural, como também no campo dos meios de comunicação, sendo nesse sentido que as cidades podem ser tratadas como elementos sociais complexos e de inúmeras dimensões (CASTELLS; BORJA, 1996). Nesse âmbito, decorrente da ordem econômica, o planejamento estratégico como metodologia de idealização e plano para as cidades, se edifica como técnica de articular novas uniões de elementos, os quais são indispensáveis às cidades que ambicionam incorporar-se na era global (MACEDO, 2002).

Entretanto, o planejamento estratégico não é uma ferramenta que foi gerada por urbanistas ou gestores municipais, seus conceitos e instrumentos foram extraídos da prática empresarial, a qual se originou das experiências da ciência militar (GUELL, 2006). Embora, a partir da década de 60, o planejamento estratégico tenha surgido no campo empresarial como uma ferramenta de conquista de mercado, foi nas décadas posteriores, que houve uma disseminação desse pensamento, tanto na esfera de concepções e conteúdos quanto a processos da ação, para o campo da gestão pública (DURIGUETTO, 2004/2005).

De tal modo, o planejamento estratégico pode assim ser entendido, pelo procedimento ou modo metódico de administrar as transformações e de instituir a determinada organização o melhor futuro (SANTOS, 2011). Paralelamente, o conceito dessa teoria, implica a noção de constante avaliação das alterações para que, sejam estabelecidas as melhores táticas de interferência (SIMPLíCIO, 2000). Assim, o planejamento estratégico tem como objetivo, ajudar e facilitar os responsáveis a assumir decisões, tendo o intuito de antecipar e se preparar para essas mudanças. Em vista disso, sua principal característica, é a flexibilidade, a qual permite uma acomodação necessária perante as incertezas (TERENCE, 2002). Dessa forma, pode ser aceito como uma ferramenta mais maleável que o planejamento comum, uma vez que tem como estratégia selecionar apenas algumas características necessárias a serem tomadas, estimulando os agentes a ponderar o que é realmente importante (ALDAY, 2000).

Nesse âmbito, para Farias (2009), o planejamento estratégico abre portas para o progresso da qualidade de vida do meio urbano, o que também acaba incidindo em seus arredores. Nesse aspecto, se articula 0 planejamento estratégico como um instrumento empregado para a melhora das decisões dos gestores, visto que, tal ferramenta serve de alicerce para ponderar o desempenho futuro das organizações (PRAZERES, 2011).

\subsection{Acupuntura Urbana: Fundamentos e Concepções}

A acupuntura utilizada na medicina, se denomina pela metodologia de inclusão e manipulação de agulhas em diversos pontos do corpo, as quais, são utilizadas para fins terapêuticos, tendo o intuito de aliviar a dor em determinado lugar (CASAGRANDE, 2014). Entretanto, advinda da técnica da medicina, a expressão acupuntura urbana, foi criada no campo da arquitetura e do urbanismo, com o intuito de usar o mesmo sentido que a técnica possui no campo medicinal, porém no âmbito das cidades, assim, preconizando o uso de pequenas e sinuosas intervenções, as quais transformariam o contexto urbano de maiores dimensões (FERREIRA, 2014).

Todavia, não se tem uma base sólida de quem objetivou a expressão "acupuntura urbana" pela primeira vez, visto que, existe três precursores que abordam essa teoria. Primeiramente, por meio da década de 70 , o arquiteto espanhol Manuel de Solà-Morales é referido por seu conceito sobre o termo. Posteriormente, o arquiteto brasileiro Jaime Lerner aplica os princípios em seus projetos na cidade de Curitiba - capital paranaense. E por último, o arquiteto finlandês Marco Casagrande, o qual reafirma e reanima o conceito da teoria (HOOGDUYN, 2014). 
Lerner e Casagrande, fundamentam a acupuntura urbana sob uma percepção orgânica da cidade. Baseada na antiga técnica chinesa, a qual consiste no corpo sendo um todo interligado, onde existem canais que se conectam aos órgãos internos; o método de cura da acupuntura incide em estimular um balanceamento de energia, para recuperar a saúde perdida de determinado lugar (CABALLERO, 2016). Na acupuntura humana, um ponto estratégico é manuseado para melhorar o corpo do paciente, da mesma maneira se ocorre nas cidades, na qual o planejador necessita saber as causas da doença da cidade, para então ser apto a definir o local a receber melhorias (GRIFONI et al, 2017).

De tal modo, pode-se definir acupuntura urbana como uma união de revitalizações e atos pontuais que podem alterar gradualmente a vida urbana. Tais intervenções auxiliam na cura de problemas no tecido urbano de forma imediata, efetiva e funcional. O termo acupuntura urbana, deve ser defrontado como uma estratégia, uma premissa, uma vez que este método, assim como outros, é um artifício, e não gera mudanças repentinas, sua metodologia é propiciar um começo, o qual se alastrará para seu entorno (FERREIRA, 2014).

Nesse âmbito, Hoogduyn (2014), explica que na técnica de acupuntura tradicional as agulhas são inseridas em locais específicos do corpo, o qual pode melhorar este ponto ou ainda um outro lugar. Entretanto, na acupuntura urbana, as intervenções, que são semelhantes as picadas, devem ser, ao contrário da medicinal, aplicadas em lugares os quais a revitalização deve acontecer, porém, isso implica em um possível efeito catalisador, o qual decorrente dessa 'picada' pode melhorar outros lugares. De tal forma, se bem idealizada e executada, uma reabilitação em determinado lugar, pode alterar totalmente o seu entorno (FERREIRA, 2014).

Não obstante, Hoogduyn (2014), ao estudar sobre os três pioneiros do termo acupuntura urbana, Manuel de Solà-Morales, Jaime Lerner e Marco Casagrande, partindo de uma postura crítica, faz uma interpretação das obras e visões de cada autor, visto que, os três precursores não advertem a mesma idealização, para então elencar oito princípios que devem ser comuns no âmbito da acupuntura urbana, sendo eles: Ponto sensível, Cenário, Ato rápido, Participação, Educação, Abordagem holística, Pequena escala e Criação de lugares (Conforme fluxograma figura 01). 


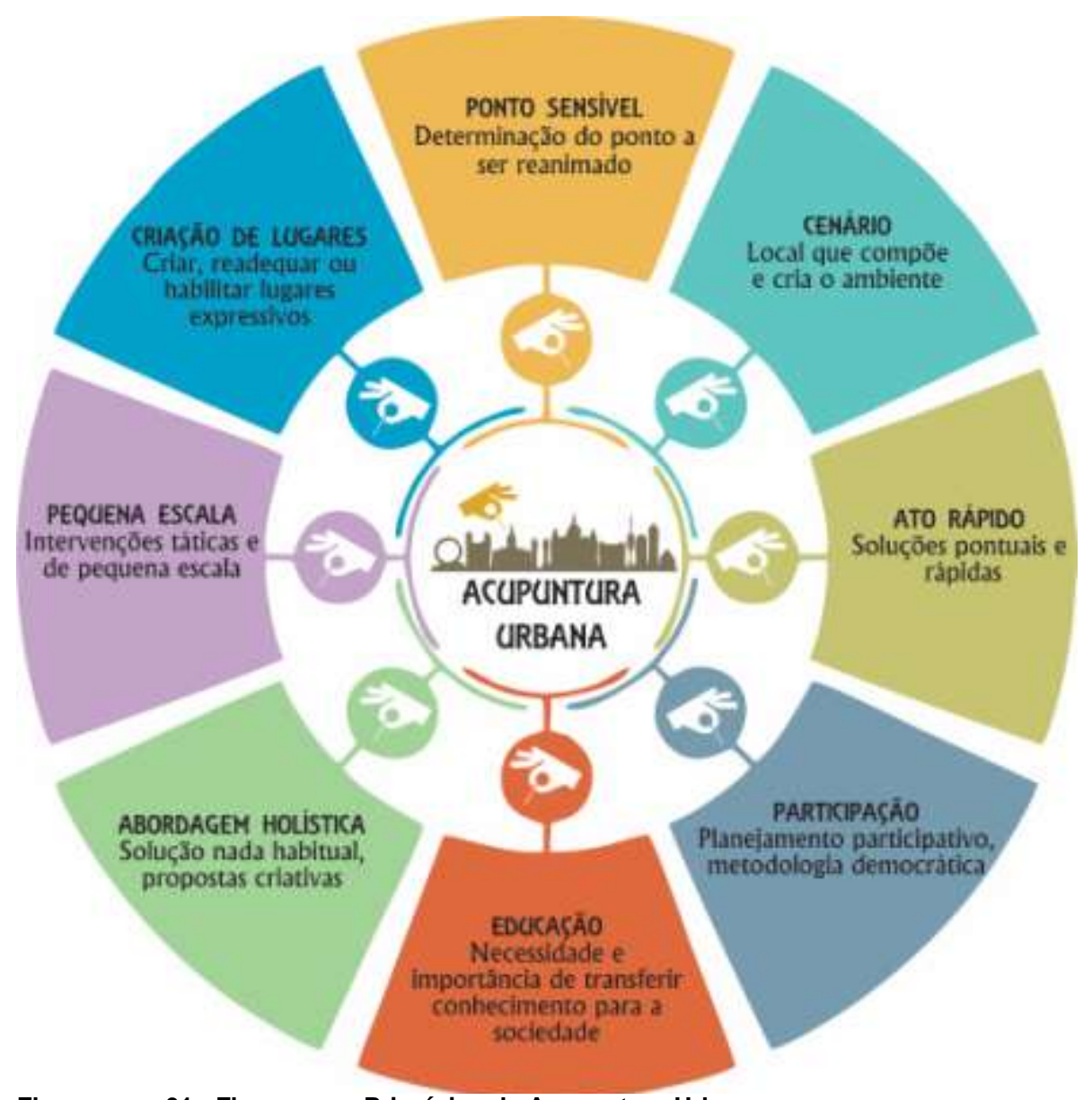

Fluxograma 01 - Fluxograma Princípios da Acupuntura Urbana

Fonte: Elaborado pela autora (2017), com base em Hoogduyn (2014)

De tal modo, adotando o proposto por Hoogduyn (2014), faz-se uma descrição dos respectivos princípios:

1. Ponto Sensível: É a determinação do ponto a ser reanimado, o qual se necessita de revitalização, podendo ser definido por um local onde se tem carência de energia, ou pelo confronto de muitas forças (HOOGDUYN, 2014). Seguindo esse aspecto, Caballero (2016) afirma, que a acupuntura urbana exerce uma ação que se compara a um planejamento tático, um micro urbanismo, de interferências particulares, as quais são minuciosamente definidos pela sua potencialidade em disseminar melhorias ao redor.

2. Cenário: Toda cidade precisa de um cenário, um local que compõe e cria o ambiente, a identidade do local (HOOGDUYN, 2014). A cidade é o cenário do encontro, o centro a partir do qual se cunham códigos de convivência (LERNER, 2013). Conforme Lerner (2013), cada cidade tem sua história, pontos e alusões, locais que competem à tradição e lembranças da cidade, que são pontos essenciais e intrínsecos a sua identidade.

3. Ato rápido: O processo de acupuntura urbana é visto como um método de rebate ao planejamento urbano demorado, visto que, tem como base soluções pontuais e rápidas (TALVISTE, 2010). Comparando à acupuntura médica, o essencial é que a picada seja rápida, do mesmo modo na acupuntura urbana se exige uma presteza e uma concisão na intervenção (LERNER, 2013).

4. Participação: Segundo Hoogduyn (2014), a acupuntura urbana é um meio de processo de planejamento participativo, visto que, esta participação objetiva uma metodologia mais democrática. De tal modo, os agentes de transformação urbana, não podem ser estimados somente pelos tradicionais tomadores de decisão, mas também pelas pessoas que vivem em determinado local (HOOGDUYN, 2014). Além disso, a acupuntura urbana trata as atividades urbanas e domínios que fazem a cidade trabalhar corretamente, apontando tanto seus aspectos naturais, quanto humanos e sociais, gerando atividades nos setores público, privado e popular (HARJOKO, 2009). 
5. Educação: Se traduz perante duas maneiras, uma diante da necessidade de compreensão da sociedade diante das perspectivas e outra pela importância de transferir conhecimento para a sociedade, uma vez que, se tem uma precisão em se compreender como a sociedade se relaciona com o ambiente (HOOGDUYN, 2014).

6. Abordagem holística: É um princípio característico da acupuntura urbana, pois tal teoria diverge do planejamento convencional. Assim, essa expressão é caracterizada por ser um problema que não deve ser tratado por uma solução habitual, e sim, por propostas criativas, sendo uma tarefa que não compete apenas a urbanistas ou planejadores, e sim a toda a população, fazendo com que, juntamente com a participação dos cidadãos, seja estabelecida essa abordagem holística (HOOGDUYN, 2014).

7. Pequena escala: A relação de pequena amplitude é uma característica acentuada das operações de acupuntura, visto que, nem sempre grandes mudanças são válidas, as vezes podem ser irrelevantes (HOOGDUYN, 2014). Dessa forma, visto sua dinâmica de projeto, a acupuntura urbana é direcionada para intervenções táticas e de pequena escala, visando aos efeitos alastradores que tal transformações pode acarretar. Embora, seja em pequeno grau, produz um desenvolvimento ecológico e social em ampla abrangência (CASAGRANDE, 2016). Todavia, a escala não é apenas limitada ao tamanho, podendo ser também referente a questão financeira de gastos com as revitalizações (HOOGDUYN, 2014).

8. Criação de lugares: A definição de acupuntura urbana é sobre reconsiderar lugares, sendo que o conhecimento da definição de um determinado local, emerge em meio a essa estratégia de planejamento, uma vez que projetos de acupuntura urbana visam criar, readequar ou habilitar lugares expressivos (HOOGDUYN, 2014). Como Lerner (2013:13) afirma: "É fundamental que uma boa acupuntura urbana promova a manutenção ou o resgate da identidade cultural de um local ou de uma comunidade. Muitas cidades hoje necessitam de uma acupuntura por que deixaram de cuidar da sua identidade cultural".

Nesse sentido, Lerner (2013) ainda afirma que, muitas cidades precisam de uma acupuntura urbana por abandonarem sua autenticidade cultural, dessa maneira, é imprescindível que uma adequada acupuntura urbana fomente a conservação ou a salvação dessa identidade cultural. Entretanto, se deve cuidar com a invenção que se faz, pois tanto na acupuntura medicinal, bem como na urbana alguns pontos ficam quentes e favorecem o tecido, enquanto outros simplesmente apagam-se (CASAGRANDE, 2014).

\section{A CIDADE DE BARCELONA/ES}

Barcelona, cidade espanhola no decorrer da sua história passou por muitos estágios de transformações urbanas. Sendo que, em 1992, a cidade sofre um denso processo de renovação urbana adotado para a realização dos Jogos Olímpicos (SÜRER, 2016). Assim, nesse capítulo se contemplará o contexto histórico e político da cidade para a elaboração desse plano e também os programas e projetos realizados.

\subsection{Olimpíadas 1992: Contexto Histórico}

Iniciada em 1975, a passagem política espanhola para a democracia aconteceu paralelamente à crise econômica geral que se vivia desde 1973 em grande parte dos países europeus (CARVALHO, 2014). Diante desses parâmetros, em meados de 1979, Barcelona/ES se deparou com muitas deficiências; molestada pelo afastamento de amplas empresas, pelo marasmo da renda e pela redução de sua estima política (PRONI et al, 2008). Nesse período, a cidade se encontrou com zonas de urbanização precárias, zonas residenciais especulativas quase sem urbanização, falta de equipamentos e espaços públicos, além da carência em transporte coletivo (MUXI, 2010).

Nesse período, Barcelona/ES ainda se encontrava sob o poder do partido socialista, o qual detinha um plano de ação que tentaria suprir as carências da periferia, utilizando para isso serviços coletivos - o metrô e também digna habitação. Assim, existia um plano entre a prefeitura de Barcelona e os governos da Catalunha e da Espanha para empregar o país em um contexto social dos principais países europeus (CARVALHO, 2014).

De tal modo, a forma que os governantes encontraram para contemplar Barcelona/ES novamente no mercado foi candidatar a cidade para sediar os Jogos Olímpicos que aconteceriam em 1992 (PRONI et al, 2008, p.15). Dessa maneira, em 1987, a cidade foi selecionada para acolher os Jogos Olímpicos. Com isso, 
tal advento mudaria inteiramente as perspectivas de ação sobre a cidade, e a escala das interferências que iria sofrer (MUXI, 2010). Entretanto, a chegada dos Jogos Olímpicos em Barcelona/ES se deparou com uma cidade em processo político de transição e concomitantemente à efetivação da União Europeia, a Espanha se encontrava em um momento único de amplo crescimento econômico devido a progressiva cooperação internacional (CARVALHO, 2014).

Dessa maneira, o fato de sediar as olimpíadas, também eclodiu como uma réplica a esse conjugado de pontos que se remetia a inclusão econômica e política espanhola, catalã e barcelonense na Comunidade Europeia. Nesse sentido, ser sede dos Jogos Olímpicos seria como um método de vincular Barcelona à Europa, sem a intermediação da capital Madri (LIMA JUNIOR, 2010). Como Lima Junior (2010:101) se refere "De fato, os preparativos para o evento serviriam de pretexto para um projeto de cidade que dava vazão às aspirações de inserção num espaço mais amplo (europeu/internacional) ".

O episódio de Barcelona como sede das Olimpíadas de 1992 era ainda mais notório, uma vez que a cidade já havia tido uma primeira tentativa de sediar em 1924 os Jogos Olímpicos, quando foi fracassada (ARAÚJO et al, 2012). Assim, essa sua conquista no sistema de seleção foi decisiva para a história da cidade, visto que Barcelona/ES introduziu uma completa programação de intervenção olímpica a qual conseguiu usufruir de diversas especialidades relacionadas aos Jogos Olímpicos (FERNANDES, 2006).

Dessa forma, esse advento colaborou com um maior anseio e necessidade de alastramento de uma imagem esportiva e positiva da cidade (ARAÚJO et al, 2012), dado que grandes eventos, como aquele, relacionavam-se expressivamente com o orgulho, com a imagem e com o desejo da localidade em passar a ser concretamente uma hegemonia local. Além disso, também fez com que a cidade abrisse portas para vários campos de atuação, como o espaço urbano, a arquitetura e até mesmo para a própria cidade (FERNANDES, 2006).

\subsection{Olimpíadas 1992: Planos e Programas}

A intitulação de uma cidade como protagonista dos Jogos Olímpicos, provoca uma tomada de decisões sobre os investimentos indispensáveis para adapta-la à efetivação do evento, nesse âmbito se considera tanto os aspectos físicos, como projetos urbanos, quanto o orgulho da população e o embate no conceito internacional da cidade (PRONI et al, 2008). De acordo com Molet (2010), os preparativos de uma cidade para receber um evento desse porte, demandam também de uma fase de prévia reflexão, verificando com isso, quais são as intercessões urbanísticas imprescindíveis e avaliando quais mudanças seriam adequadas tanto para a cidade, quanto para o evento.

Em um primeiro momento debateu-se experiências de eventos anteriores que teriam dado certo, visando, com um regular distanciamento de tempo, atos que já foram efetivados, e em cada episódio desses, avaliou-se também, como inferiram no contexto urbano. Com isso, a proposta que antes era de pequenas intervenções, as quais seriam pontuais, onde a partir dos bairros se recuperaria o tecido urbano, passou a ter grande proporção, cedendo lugar a grandes intervenções urbanísticas que direcionavam para um projeto em ampla abrangência da cidade (LIMA JUNIOR, 2010).

A idealização e o arranjo de um evento dessa magnitude, atribui notória visibilidade as suas políticas públicas, ao seu potencial econômico, comercial, cultural e turístico. Nesse âmbito, o caso das Olimpíadas em Barcelona/ES se torna emblemático por, além de outros desígnios, tratar também sobre o referencial da industrialização e dos movimentos contemporâneos sociais, culturais e políticos que se vivia na Espanha, e sobretudo, sobre sua evidente melhoria local, a partir do significativo desempenho da cidade no contexto internacional (CARVALHO, 2014). Além disso, muitos projetos tinham e foram cumpridos e outros administrados, embora uma grande maioria não fosse diretamente necessário para os jogos, contudo, foi exatamente esse fato, um dos essenciais efeitos sob a cidade "deixar como legado dos Jogos Olímpicos o maior número de investimentos totalmente úteis" (PRONI et al, 2008).

Nessa conformidade, em meio ao andamento de pretensão e preparação das Olimpíadas, Jordi Borja, geografo, urbanista e vice-presidente de Barcelona, conjuntamente com Manoel de Forn, admitiram a organização e composição do plano estratégico para o desdobramento e progresso da cidade em prol dos Jogos Olímpicos de 1992 (FERREIRA, 2014). Para a elaboração do projeto olímpico, estava previsto doze áreas, contudo ele atuou somente sobre quatro, tendo como base de escolha, o equilíbrio territorial, sendo que, tais planos foram realizados sobre os bairros que se deparavam na desvantagem em confrontação aos demais (MUXI, 2010). Paralelamente, outra questão emblemática, foi que os Jogos Olímpicos se 
distinguiram por sua descentralização, visto que foram destinadas uma série de cidades como sub sedes, entre elas as regiões da Catalunha, Valência e Aragão (PRONI et al, 2008).

Os investimentos para as Olimpíadas significaram uma ótima circunstância para amplos projetos de infraestrutura, entre eles a estação de tratamento de água, a nova base de eletricidade e novos sistemas de esgoto, uma vez que sem esta oportunidade tais progressos delongariam muito tempo para serem concretizados. Todavia, esses projetos podem ser menos visíveis, entretanto são indispensáveis para o desenvolvimento dos planos que são evidentes a todos, sendo que, é a partir dessa base bem elaborada que se dá sustentação para projetos como: as acomodações desportivas, a reconquista e concepção de praias e passeios marítimos, as avenidas perimetrais, entre outros (MUXI, 2010).

Nesse âmbito, os fundamentais projetos em termo estrutural na cidade foram: a edificação do anel rodoviário, que era o caminho principal para explorar a circunferência da cidade; a abertura para o mar, com a constituição da vila olímpica; e a criação das zonas olímpicas e de diversos novos centros (PRONI et al, 2008). Nesses parâmetros, Barcelona entre os anos de 1988 a 1991 observou e suportou uma cidade estressada e desordenada que era preenchida por obras, no entanto, ao mesmo tempo que a população vivia esse momento, havia ainda um sentimento de surpresa e esperança (REIS, 2010).

A construção dos anéis viários para a cidade foi um dos principais elementos, visto que envolveram toda Barcelona/ES, promovendo melhoras no deslocamento dos veículos (IGLESIAS, 2010). O projeto viário idealizado otimizou a reserva de solo para concretizar um novo conceito de via perimetral, sendo sugerido um sistema duplo. O primeiro era edificado em trincheira, o qual daria suporte a circulação expressa, sendo constituída com três pistas em cada sentido e sem semáforos. Já o segundo, mais complexo, era composto por duas ruas que seriam paralelas na superfície, possuindo duas pistas em cada sentido, as quais se ligariam com a rede viária local. Dessa maneira, entre os dois sistemas são aparelhados assíduos atrelamentos, sendo que nos $42 \mathrm{~km}$ de Ronda existem trinta elos de entrada e saída em ambos sentidos de circulação. Tal efeito permitia vincular pontos próximos de duas maneiras diferentes, uma por meio da via rebaixada e outra pelas vias em mesmo nível da cidade (MOLET, 2010) (Figura 01).

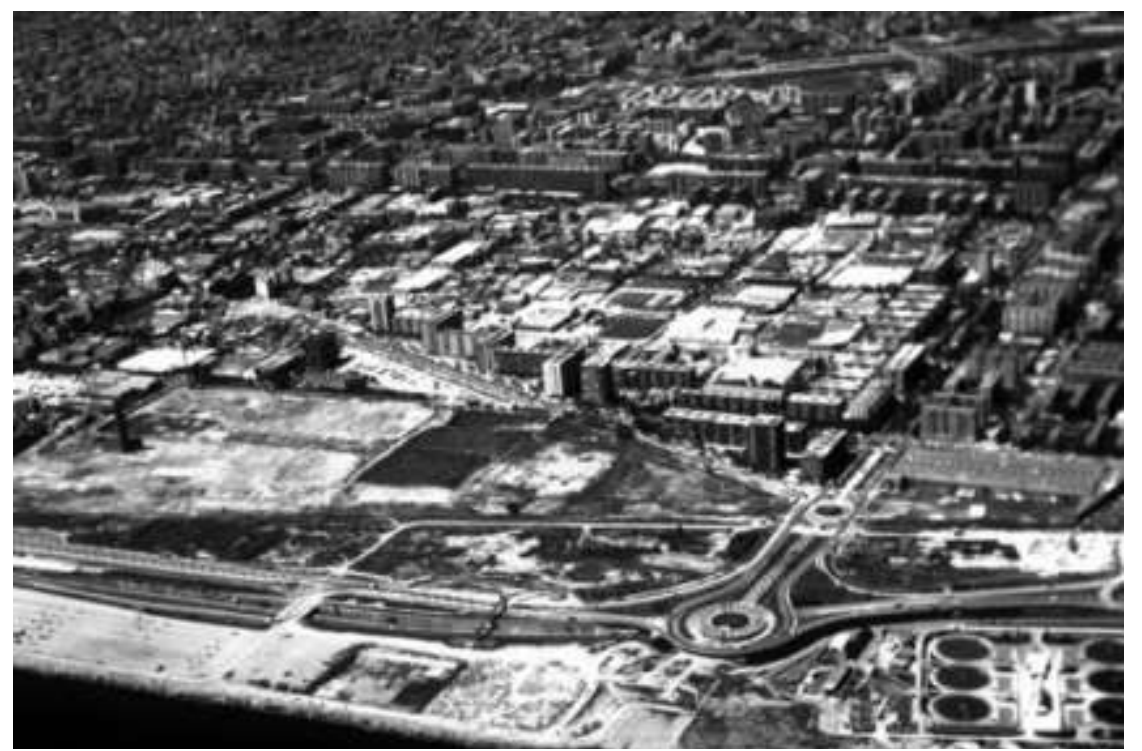

Figura 01 - Estrutura viária Barcelona/ES

Fonte: Molet (2010)

Quanto ao mar, Barcelona/ES restabeleceu, redescobriu e apoderou-se do seu bem, uma vez que era uma cidade que possuía mar e não o usufruía. Assim, com o advento dos Jogos Olímpicos a cidade transformou totalmente a orla marítima (IGLESIAS, 2010). Em 1987, com a edificação de um novo porto, que seria o meio de transação entre a antiga cidade, já se iniciava uma prática de interferência na orla marítima que unificaria a cidade ao mar. Tais projetos visavam tanto modificações de proporção intermediária, como aquelas de maior competência. Sendo que tais intercessões de pequena escala seriam para reavivar a relação de Barcelona/ES com o mar (ZAPATEL, 2011). Com isso, desde o advento dos jogos olímpicos a orla marítima passou a ser uma das principais atrações de Barcelona, a qual possui inacabáveis calçadões que abrangem todo o litoral, com vastas praias que foram reconquistadas. Entretanto, não foi apenas as praias que se sobressaíram, o porto se constituiu como um centro esportivo e de lazer, com ancoradouros, 
bares, shoppings, restaurantes e principalmente, como uma nova área turística (IGLESIAS, 2010) (Figura 02).

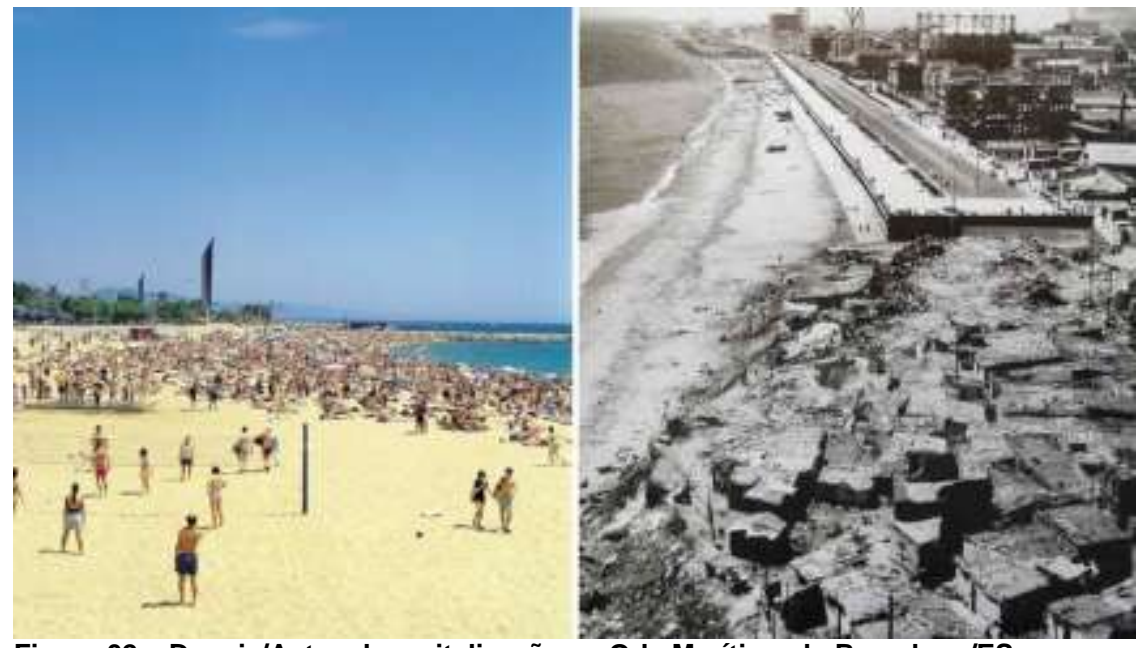

Figura 02 - Depois/Antes da revitalização na Orla Marítima de Barcelona/ES

Fonte: Portal G1 - Globo Esporte (2016) Foto: J. Trullàs / Barcelona Turisme e Reprodução

Essa reconquista do litoral, foi apenas o princípio do progresso, fez-se necessário que esse desenvolvimento continuasse, uma vez que a intervenção olímpica não teve força hábil para conduzir a revitalização em toda a extensão da orla marítima da cidade. Entretanto, a Vila Olímpica concebida, após ser utilizada por um mês (tempo de duração das Olimpíadas), se tornou um bairro pertencente à cidade em janeiro de 1993, esse detém um setor residencial de categoria, com centralização de atividades e serviços, amplos espaços públicos e facilidade de acesso e mobilidade, favorecendo a região com investimentos, consumidores e usuários, não permitindo que ela se submergisse (FERNANDES, 2006).

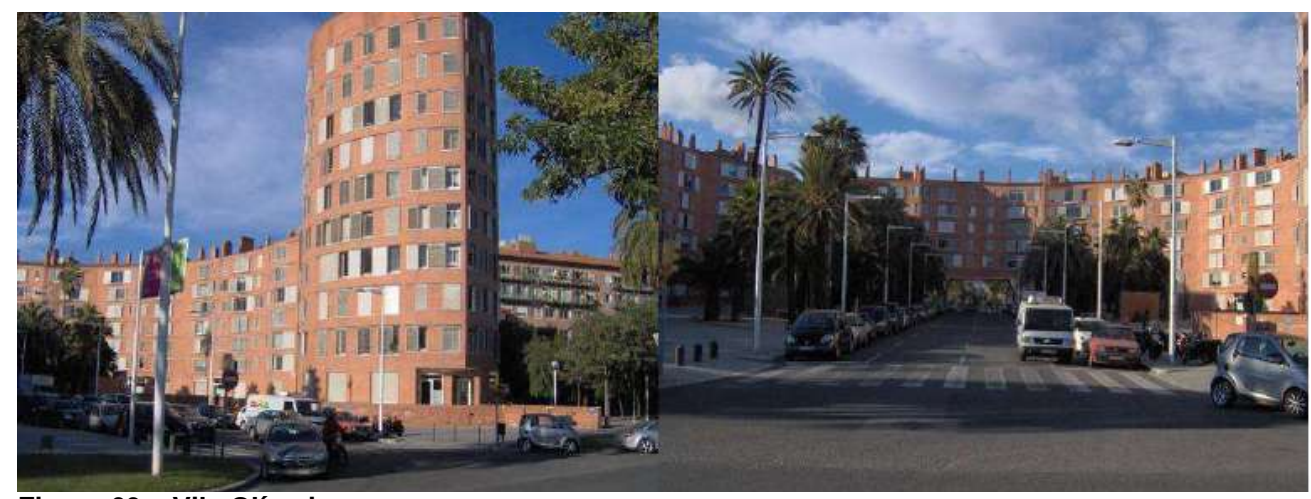

Figura 03 - Vila Olímpica

Fonte: Fernandes (2006)

Dessa maneira, Barcelona/ES foi uma cidade que ao agenciar as olimpíadas de 1992, soube consagrar seu ensejo para realizar transformações nas estruturas urbanas e efetivar suas atividades econômicas (ZANETTI, 2005). Como Proni et al (2008:25) relata: "Em suma, Barcelona demonstrou não só que os Jogos podiam dar lucro para os organizadores, mas que podiam ser utilizados como um catalisador para 0 crescimento econômico e para a modernização urbana, legitimando investimentos que podem beneficiar o conjunto da população. Além disso, pela natureza dos Jogos Olímpicos, Barcelona conseguiu apagar a falsa imagem de uma cidade provinciana, isolada pelas idiossincrasias da Catalunha, tendo sido capaz de se afirmar diante da opinião pública internacional, assumindo a imagem muito positiva de uma metrópole cosmopolita, contemporânea, aberta à interação de diferentes culturas. $E$ isto não apenas ampliou sua força de atração sobre as grandes empresas (como centro de negócios) como impulsionou seu desenvolvimento no campo do turismo internacional".

As mudanças em Barcelona representaram além dos apontadores, um cartão de visita internacional para a Espanha democrática, uma vez que o país conduziu uma imagem dinâmica e popular, a qual rompeu com os clichês até então definidos, fazendo, ainda, com que o país se apresentasse como europeu e central diante da União Europeia e da comunidade internacional (CARVALHO, 2014). 


\section{ANÁLISES E DISCUSSÕES}

Independentemente da escala, muitas cidades tem o desejo e aspiração por uma identificação própria, buscando estabelecer um marco único de identidade, visando com isso, fomentar as relações urbanas, sociais e econômicas (CAIXETA; FROTA, 2006). Nesse sentido, Barcelona/ES, tinha notória necessidade de transformação, com isso, o plano de 1992 foi uma série de projetos urbanos específicos, os quais previam a recuperação e a reocupação das áreas, juntamente com uma ampla transformação e alteração para se tornar uma cidade nova e que pertencesse aos cidadãos.

Como Caixeta; Frota (2006) afirmam: "A modificação da paisagem urbana de Barcelona dar-se-ia através do abandono de um modelo de planejamento quantitativo que tinha por base a subordinação dos aspectos morfológicos de desenho, aos instrumentos e técnicas de controle urbanístico da forma urbana. Assim, o modelo de planejamento global deu lugar à escolha de um repertório de ações pontuais, em diferentes escalas, que obedeceu a uma análise criteriosa e bem definida da estrutura da cidade" (CAIXETA; FROTA, 2006). Barcelona/ES já possuía uma grande extensão e o que prevalecia na cidade naquele momento, era a ideia de reparar pontualmente algumas áreas já existentes e estabelecer um processo urbano apropriado a atuar efetivamente sobre uma cidade densa e já construída.

Molinar; Rogério (2015) mostram que "Planejar é um processo e todo processo gera mudanças, porém estas não aparecem de forma imediata, mas é um pontapé para que algo aconteça" (MOLINAR; ROGÉRIO, 2015). Essa afirmação além de contemplar e definir planejamento, pode ser acatada ainda como uma acepção para o termo acupuntura urbana. Tal teoria, embora nascida muito tempo após as primeiras intervenções de planejamento, é um termo conectado e integrado as questões urbanas, visto que é uma ramificação do mesmo, e um método baseado em que pequenas intervenções pontuais em um espaço, resultem em impactos positivos para a cidade e seus habitantes.

Hoogduyn (2014) afirma que essas intervenções não miram um ponto fixo e devem ser vistas como um processo continuo que permanecem abertos para usos alternativos. O ponto básico da acupuntura urbana é oferecer instrumentos para que mudanças aconteçam, podendo ser vista como um começo, o qual funciona como uma faísca que se propaga ao entorno.

Diante dos conceitos, é notório como as duas teorias de modificação urbana, o planejamento urbano e a acupuntura urbana, mesmo dadas em épocas distintas, estão intimamente ligadas e são bases para alterações e melhorias no campo das cidades. Carvalho (2008) explica que "os discursos e imagens produzidos por uma cidade são construções sociais, e dessa forma, devem ser analisados em seu contexto histórico juntamente com seus autores, receptores e condicionantes favoráveis para seu desenvolvimento". Dessa forma, é baseado nessa preposição que a análise do trabalho se sustenta, implicando que o planejamento executado sobre Barcelona/ES pode ser considerado como um episódio de acupuntura urbana.

Hoogduyn (2014) em sua dissertação defende que a base da acupuntura urbana se dá a partir de oito pontos, sendo eles: 1- Ponto Sensível, 2- Cenário, 3- Ato rápido, 4- Participação, 5- Educação, 6Abordagem Holística, 7- Pequena Escala e 8- Criação de Lugares, o autor ainda explica que esses princípios não são independentes uns dos outros, e sim o contrário, eles exercem influência uns sobre os outros, podendo ainda se sobreporem.

Com isso, partindo desses princípios propõe-se uma comparação e análise desses oito pontos estipulados por Hoogduyn (2014), com o contexto, idealizações e transformações que o planejamento para as Olimpíadas de 1992, teve sobre Barcelona/ES. A partir disso, para melhor didática, foi elaborado o seguinte fluxograma, baseado no fluxograma 01, para relacionar e conferir os dados: 


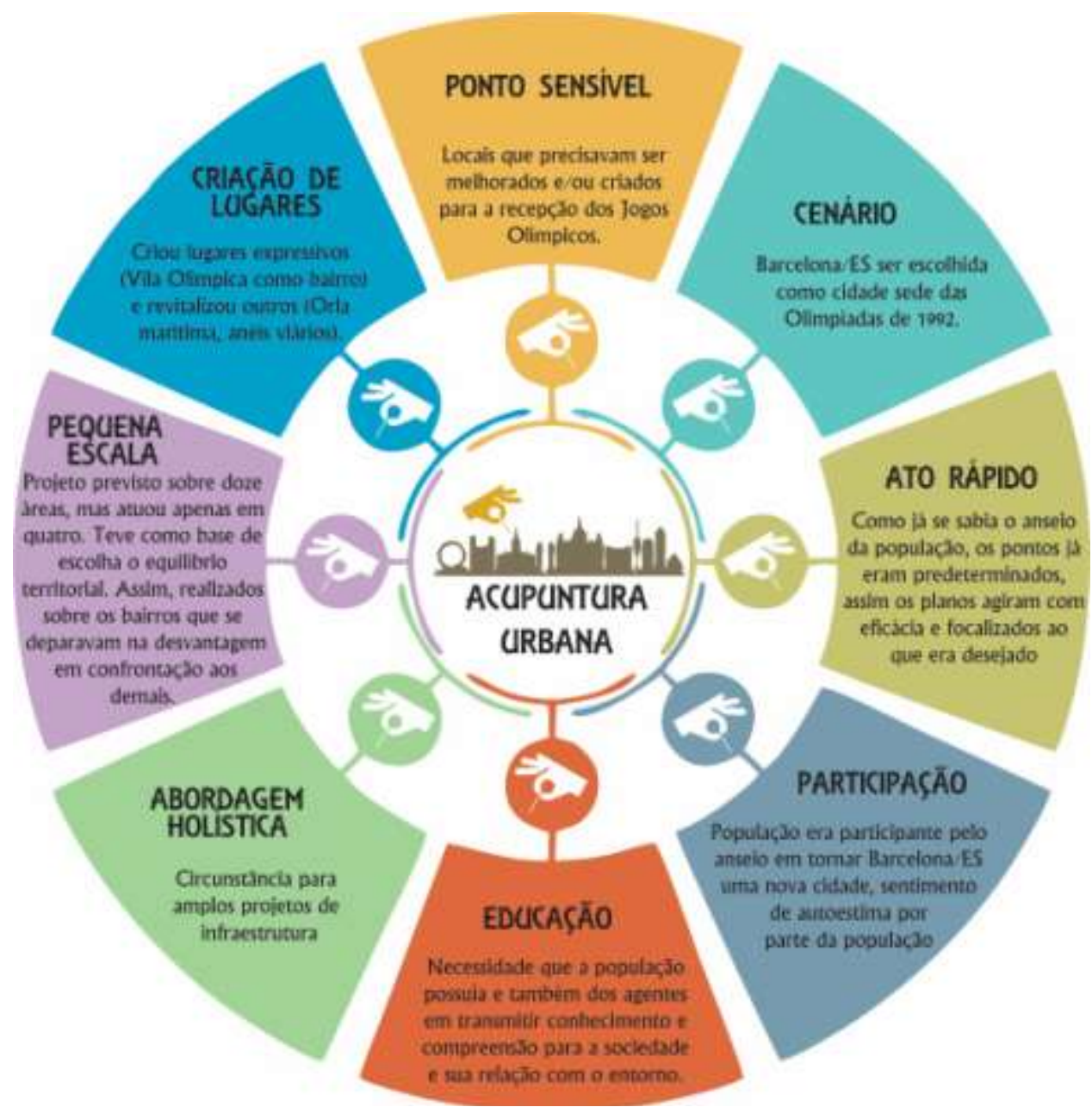

Fluxograma 02 - Relação do planejamento com acupuntura urbana

Fonte: Elaborado pela autora (2017), com base em Hoogduyn (2014) e nos demais dados da pesquisa.

Conforme Jaime Lerner, a acupuntura urbana é um conjugado de ações pontuais e de revitalização que podem alterar progressivamente a vida na cidade. Perante esta relação, se observa como o plano se encaixa com grande participação sobre os princípios abordados por Hoogduyn (2014). Barcelona/ES conseguiu agenciar reformas pontuais que influenciaram a cidade como um todo e a avigoraram como um marco para ela mesma e para o urbanismo em geral.

É possível notar que, a linguagem utilizada foi de caráter relativamente forte no porto de inserção no meio, o que ocasionou a drástica e excelente transformação local. Após as Olimpíadas de 1992, a cidade passou a vivenciar um novo panorama em relação a qualidade de vida, reconhecimento nacional e sentimento de autoestima por parte da população. Além disso, é notório a capacidade de transformação da identidade da cidade, visto que tal planejamento se adequa perfeitamente como acupuntura urbana pelo modo de resgate, de locais até então não utilizado, e também, no resgate pontual de locais degradados ou esquecidos.

Nóvoa (1998) explica que "No desenvolvimento urbano de uma cidade, é quase impossível ter um desenvolvimento sustentado, isto é, graduado e progressivo no tempo, mas as circunstâncias socioeconômicas determinam saltos qualitativos intercalados com períodos de estagnação", nesse âmbito, a força da ideia sempre esteve presente no desenvolvimento urbano de Barcelona/ES, não deixando que a cidade se submergisse diante do que já havia acontecido. Assim, tal episódio é relativamente encaixado sobre o ponto crucial da acupuntura urbana, o qual garante que o efeito não seja pontual e passageiro e sim desencadeador de novas possibilidades.

Segundo Rossi (2001) "A forma da cidade é sempre a forma de um tempo da cidade, e existem muitos tempos na forma da cidade". Barcelona/ES é uma cidade que pode ser resumida por essa frase, a cidade teve muitos tempos, muitos planejamentos totalmente diferentes e soube lidar com cada um em seu momento, tirando o melhor proveito em cada estágio, e sendo marcada pela história e forma da cidade diante deles. Ademais, a cidade ainda não deixou que seu magnífico êxito no plano de 1992 fosse 
submergido, visto que até os dias atuais Barcelona/ES ainda é reconhecida e seguida como exemplo mundial diante de seus planos.

Nesse âmbito, obtendo resposta ao problema de pesquisa: De que forma o planejamento estratégico da cidade de Barcelona/ES pode ser considerado como um pleno exercício de caso de acupuntura urbana? Confirma - se a hipótese inicial a qual era definida por: A cidade de Barcelona/ES, em um de seus planejamentos mais marcantes, o plano para as Olimpíadas de 1992, alude a um íntegro caso de acupuntura urbana. Assim, visando a síntese dos conceitos e elementos apresentados, é verificável a intrínseca relação entre os temas abordados com a acupuntura urbana, sendo que se encaixa perfeitamente na definição que o arquiteto Jaime Lerner dá para o termo.

\section{CONSIDERAÇÕES FINAIS}

Em resgate sintético da pesquisa, o trabalho aborda na introdução os elementos fundamentais que o estruturam, os quais tem o desígnio de expor os aspectos gerais, permitindo a compreensão do motivo de sua execução, bem como dos seus objetivos, problema, hipótese e finalidades da pesquisa.

No decorrer do trabalho são apresentados, diante de uma ampla pesquisa bibliográfica, as teorias e conceitos do planejamento estratégico, juntamente, com os princípios da acupuntura urbana. Posteriormente, se explora o contexto histórico e o plano e os projetos do planejamento para as Olimpíadas de 1992.

Apresentando esses quesitos, atende - se aos objetivos específicos da presente pesquisa, assim, possibilitam responder ao problema instigador da pesquisa, que era dado por: De que forma o planejamento urbano e estratégico da cidade de Barcelona/ES pode ser considerado como um pleno exercício de caso de acupuntura urbana?

Nesse sentido, se percebe, diante das análises que é notório como ambos os planejamentos se encaixam com êxito sobre os princípios defendidos pela acupuntura urbana, podendo assim, comprovar a hipótese inicial da presente pesquisa, a qual era definida pela afirmação de que: A cidade de Barcelona/ES, em seus dois mais marcantes planos urbanos, o de Cerdá e o das Olimpíadas de 1992, alude a um íntegro caso de acupuntura urbana.

\section{BIOGRAFIA}

ALDAY, H. E. C. (2000). O Planejamento Estratégico dentro do Conceito de Administração Estratégica. Rev. FAE (Curitiba), 02, 09-16.

ARAÚJO, A. C., DIAS, M. A. y CABRAL, B. G. A. T. (2012). Marathon - Notas sobre a representação do esporte moderno. Universidade Federal do Rio Grande do Norte. Esporte e Sociedade Marathon, ano 7, n.19.

CABALLERO, A. P. (2016). Acupuntura Urbana: Intervención en la ciudad y participación: Cuatro experiencias. Universidade Politécnica de Valência - Escola Técnica Superior de Arquitetura - Departamento de Planejamento Urbano.

CAIXETA, E. M. M. P.; FROTA, J. A. D. (2006). Projetar a Paisagem Contemporânea e Reconstruir Territórios - Barcelona (1980-90). Anais do XVIII Encontro Regional de História - O historiador e seu tempo. ANPUH/SP - UNESP/Assis.

CARVALHO, A. S. (2008). Curitiba: Imagem do planejamento ou planejamento da imagem?. Monografia (História Setor de Ciências Humanas, Letras e Artes) Universidade Federal do Paraná. Curitiba.

CARVALHO, J. M. (2014). Os Jogos Olímpicos, a Cooperação Descentralizada e a Aplicação de Políticas Públicas: O Modelo De Barcelona 92 para O Rio De Janeiro 2016. Dissertação Mestre em Ciências Programa de Pós-Graduação em Relações em Internacionais, Universidade de São Paulo, São Paulo.

CASTELLS, M., BORJA, J. (1996). As Cidades como Atores Políticos. En Novos Estudos, CEBRAP, no45, (152-166) São Paulo. 
DIAS, S. I. S. (2009). Sistema de planejamento para implementação e monitoramento de planos diretores em municípios brasileiros. Tese (Doutorado em Gestão das Organizações) - Programa de Pós-Graduação em Engenharia de Produção, Universidade Federal de Santa Catarina, Florianópolis.

DURIGUETTO, M. L. (2004/2005). A ideologia privatista do planejamento estratégico de cidades. Libertas Revista da Faculdade de Serviço Social (Juiz de Fora), especial, 68 - 91.

FARIAS, L. (2009). Planejamento Estratégico, Estatuto da Cidade e Plano Diretor: Métodos e instrumentos de organização e gestão do espaço urbano. Caminhos de Geografia - Revista Online (Uberlândia), 32, 162170.

FERNANDES, S. A. (2006). Os Jogos Olímpicos como Instrumento de Planeamento Urbano. Dissertação (Mestrado em Projecto e Planeamento do Ambiente Urbano) Faculdade de Arquitectura e Urbanismo da Universidade de São Paulo. Faculdade de Arquitectura e Urbanismo da Universidade de São Paulo, Porto.

FERREIRA, A. M. A. (2014). Cidades Criativas: Uma estratégia para a regeneração da Baixa de Coimbra. Dissertação (Mestrado Integrado em Arquitetura) - Faculdade de Ciências e Tecnologias da Universidade de Coimbra.

GIL, A. C. (2008). Métodos e Técnicas de Pesquisa Social. São Paulo: Atlas.

GÜELL, J. M. F. (2006). Planificación estratégica de Ciudades: Nuevos instrumentos y procesos. Barcelona: Editorial Reverté.

HOOGDUYN, R. (2014). Urban Acupuncture, Revitalizing urban areas by small scale interventions. Dissertação (Programa de Mestrado em Planejamento Espacial com ênfase em Design Urbano na China e na Europa) - Faculdade de Ordenamento do Território, Blekinge Tekniska Högskola, Estocolmo.

LAMAS, J. M. R. G. (2000). Morfologia Urbana e Desenho da Cidade. FCG- Fundação Calouste Gulbenkin.

LERNER, J. (2013). Acupuntura Urbana. Rio de Janeiro: Record.

LIMA JUNIOR. P. N. (2010). Uma estratégia chamada "Planejamento Estratégico": Deslocamentos espaciais e a atribuição de sentidos na teoria do planejamento urbano. Rio de Janeiro: 7Letras

MACEDO, V. L. (2002). O Passado de Volta: Planejamento Estratégico, Mercantilização do Espaço Público e Desigualdade Urbana. Dissertação (Mestrado em Planejamento Urbano e Regional) Universidade Federal do Rio de Janeiro, Rio de Janeiro.

MARCONI, M. A. y LAKATOS, E. M. (2003). Fundamentos de Metodologia Científica. São Paulo: Atlas.

MOLET, R. F. (2010). Planos, Projetos, Eventos: Barcelona 1992 - 2002. MEGA EVENTOS. ArqTexto 17. Departamento de Arquitetura y PROPAR Universidad Federal de Rio Grande do Sul. Porto Alegre, 124-137.

MOLINAR, D. R., ROGÉRIO, M. S. (2015). A Cidade nos Faz Pensar. XVII Seminário Internacional de Educação no Mercosul. UNICRUZ (Universidade da Cruz Alta).

MUXI, Z. (2010). Episódios da Transformação Urbana de Barcelona. ArqTexto 17. Departamento de Arquitetura y PROPAR Universidad Federal de Rio Grande do Sul. Porto Alegre, 104-123.

NÓVOA, M. (1998). Una reflexión sobre la recente transformación de Barcelona. Revista da Faculdade de Letras-Geografia (Porto). I Série, 61-75.

PRAZERES, A. (2011). Planejamento Estratégico: Um estudo sobre sua contribuição na gestão das organizações. Revista e-Estudante - Electronic Accounting and Management (Pato Branco-PR), 03, 01-14.

REIS, A. C. F. (2010). Cidades Criativas, Soluções Inventivas: o papel da Copa, das Olimpíadas e dos museus internacionais. São Paulo: Garimpo de Soluções; Recife: FUNDARPE.

ROSSI, A. (2001). A Arquitetura da Cidade. São Paulo: Martins Fontes. 
SANTOS, A. E. (2014). Do Surgimento da Cidade ao Processo Deconurbação: Elementos Teóricos Para Análise. Anais do VII Congresso Brasileiro de Geógrafos, Vitória.

SÜRER, I. A. (2016). Public Space in the Image of Barcelona in Post-Dictatorship Period. International Journal of Social Science and Humanity, 6, 446-450.

TALVISTE, M. (2010). A thought of a new place to interac. Master Thesis in Landscape Architecture. Department of Landscape Architecture Swedish University of Agricultural Sciences, Alnarp.

TERENCE, A. C. F. (2002). Planejamento estratégico como ferramenta de competitividade na pequena empresa: Desenvolvimento e avaliação de um roteiro prático para o processo de elaboração do planejamento. Dissertação (Mestre em Engenharia de Produção) - Escola de Engenharia de São Carlos, Universidade de São Paulo, São Carlos.

YIN, R. K. (2001). Estudo de Caso: Planejamento e métodos. Porto Alegre: Bookman.

ZANETTI, V. Z. (2005). Planos e projetos ausentes: desafios e perspectivas da requalificação das áreas centrais de São Paulo. Tese (Doutorado em Arquitetura e Urbanismo) Faculdade de Arquitetura e Urbanismo - Universidade de São Paulo, São Paulo.

ZAPATEL, J. A. (2011). Barcelona: Transformação Urbanística (1979-1992). Florianópolis: Ed. da UFSC.

\section{FONTES ELETRÔNICAS}

CASAGRANDE, M. (2014) Paracity: Urban Acupunture. International Conference, Bratislava, novembro, 2014. < https://www.researchgate.net/publication/279058320_Paracity_Urban_Acupuncture?enrichld=rgreq8e8aa9ee8b1c9c2478700dbcd4925eba-

XXX\&enrichSource=Y292ZXJQYWdIOzI3OTA1ODMyMDtBUzoyNDM0NDA1OTIwOTMxODRAMTQzNTA1 MjE2ODMzMA\%3D\%3D\&el=1_x_2\&_esc=publicationCoverPdf> (Consulta 10/04/2017).

- (2016): From Urban Acupuncture to the Third Generation City. Journal of Biourbanism, IV. < https://www.researchgate.net/publication/309741134_From_Urban_Acupuncture_to_the_Third_Generation_ City> (Consulta 12/04/2017).

GRIFONI, R. C., OTTONE, M. F. y PRENNA, E. Tomographic Environmental Sections for Environmental Mitigation Devices in Historical Centers. Energies, v.10. Disponível em: <http://www.mdpi.com/19961073/10/3> (Consulta: 22/04/2017).

HARJOKO, T. Y. (2009). Urban Acupuncture: An Alternative. Purposive intervention to urban development to generate sustainable positive ripples for an 'Aided Self-Help' Kampung Improvement. Assentamentos informais e habitação a preços acessíveis, p.163-172. Disponível em < https://www.irbnet.de/daten/iconda/CIB_DC25384.pdf> (Consulta: 18/04/2017).

IGLESIAS, X. (2010). O cenário pós Jogos Olímpicos de Barcelona '92. Instituto Nacional de Educação Física da Catalunha (Universidade de Barcelona). Disponível em < http://www.gr.unicamp.br/ceav/revista/content/pdf/Escenario_post_Barcelona92_Iglesias_traduzido.pdf> (Consulta 06/05/2017).

PRONI, M. W., ARAUJO, L. S. y AMORIM, R. L. C. (2008). Leitura Econômica dos Jogos Olímpicos: Financiamento, Organização e Resultados. IPEA (Instituto de Pesquisa Econômica Aplicada) Texto Para Discussão $\quad N^{\circ} \quad 1356$. Rio de janeiro. Disponível em < http://repositorio.ipea.gov.br/bitstream/11058/1533/1/TD_1356.pdf > (Consulta 07/05/2017).

SANTOS, M. O. G. (2011). Texto de apoio sobre planeamento estratégico aplicado às organizações sem fins lucrativos. Évora. Disponível em: http://home.uevora.pt/ mosantos/download/PlaneamEstrategONGS_28Jul11.pdf> (Consulta: 22/04/2017).

SIMPLíciO, M. D. V. M. (2000). A importância actual do Planeamento Estratégico e das Cidades Médias. Repositório Universidade de Évora. 
$<$ http://dspace.uevora.pt/rdpc/bitstream/10174/2684/1/Importancia_Planeam_Estrategico_Cidades_Medias.p df> (Consulta: 19/04/2017). 